\title{
Granulomatous Lobular Mastitis: Clinicopathologic Presentation of 90 Cases
}

\author{
Mine ÖZŞEN ${ }^{1}$ iD, Şahsine TOLUNAY' ${ }^{\text {iD }, ~ M . ~ S ̧ e h s u v a r ~ G O ̈ K G O ̈ Z ² ~ i D ~}$
}

Department of ${ }^{1}$ Pathology, ${ }^{2}$ Breast Surgery, Uludag University Faculty of Medicine, BURSA, TURKEY

\begin{abstract}
Objective: Granulomatous lobular mastitis is a rare benign chronic breast disease first described by Milward in 1970, and then by Kessler and Wolloch in 1972. In this study, we aimed to present clinicopathologic features of granulomatous lobular mastitis with literature data.

Material and Method: In this study, the archives of Uludag University Medical Faculty Department of Pathology were screened for granulomatous lobular mastitis cases between 2005 and 2017.

Results: A total of 90 patients with granulomatous lobular mastitis diagnosed between 2005 and 2017 were identified. All of the cases were female. The mean age was 34+8.3 (range 21-60 years). There was sarcoidosis in one case and tuberculosis in another case, but no systemic disease was found in the charts of the other cases. Histopathological evaluation of 90 cases revealed non-necrotizing granulomas involving lobule-restricted, epithelioid histiocytes and Langhans-type multinuclear giant cells. There was no case of necrosis, including our only case with a history of tuberculosis.
\end{abstract}

Conclusion: We conclude that our granulomatous lobular mastitis cases have similar characteristics with the series reported earlier, when all features are taken into consideration.

Key Words: Granulomatous mastitis, Breast diseases, Inflammation

\section{INTRODUCTION}

Granulomatous lobular mastitis is a rare benign chronic breast disease first described by Milward in 1970, and then by Kessler and Wolloch in $1972(1,2)$. The term granulomatous lobular mastitis was recommended by Going in 1987 as being more specific than idiopathic granulomatous mastitis or simply granulomatous mastitis $(3,4)$.

Today, based on the etiology, it is possible to classify these cases in two groups as granulomatous lobular mastitis and specific granulomatous mastitis. Although it is unclear yet, it is thought that various microbiological agents can play a role in the etiology of granulomatous lobular mastitis together with autoimmunity, especially alpha 1 -antitripsin deficiency, oral contraceptive use, gestation and breastfeeding, hyperprolactinemia, smoking, diabetes mellitus, local trauma and irritants (5). Tuberculosis, sarcoidosis, Wegener's granulomatosis, syphilis, Corynebacteria infection, foreign body reaction, vasculitis, fungal and parasitic infections are among the causes of specific granulomatous mastitis (4).
(Turk Patoloji Derg 2018, 34:215-219)

Received : 23.11.2017 Accepted : 27.04.2018
The fact that the reports generally refer to patients with complaints of a unilateral mass and this complaint is accompanied by findings that suggest malignancy such as nipple tears, orange-peel sign and growth in lymph nodes, usually reminds one of breast carcinomas (5). While granulomatous lobular mastitis can mimic abscess and breast cancer clinically and radiologically, there are also cases in the literature where granulomatous lobular mastitis and breast carcinoma coexist (6-9).

\section{MATERIALS and METHODS}

The study included patients with granulomatous lobular mastitis diagnosed at Uludag University Medical Faculty Pathology Department between January 2005 and August 2017. The findings were confirmed by reviewing the Hematoxylin-Eosin (HE) stained sections of the 90 cases and the immunohistochemical (pan-cytokeratin, Calponin, CD45, CD68) and histochemical (Acid Fast, Gram, PAS) study preparations in the existing cases.

Correspondence: Mine ÖZŞEN

Uludag University Faculty of Medicine,

Department of Pathology, BURSA, TURKEY

E-mail: m.isikoglu@hotmail.com Phone: +90 2242953680 


\section{RESULTS}

A total of 90 patients with granulomatous lobular mastitis diagnosed between 2005 and 2017 were identified (Table I). All of the cases were female. The mean age was $34 \pm 8.3$ (range 21-60 years).

There was sarcoidosis in one case and tuberculosis in another case, but no systemic disease was found in the resumes of other cases.

In 63 (38.9\%) cases, the mass was the most frequent type of presentation; followed by pain in $33(20 \%)$ cases, rash in 32 $(19.8 \%)$ cases, discharge in $24(14 \%)$ cases and sensitivity in $7(4 \%)$ cases. There were also 2 distinct cases, with presentation types of nipple inversion and temperature rise. During presentation, 3 cases were pregnant and 3 cases were in the lactation period. In other cases, there was no such history at the time of diagnosis.

Of the lesions, 43 were in the left breast and 38 were in the right breast. 9 lesions were found in both the right and left breasts. Involvement was limited to the upper internal quadrant in 17 cases, upper external quadrant in 30 cases, lower internal quadrant in 14 cases, lower external quadrant in 19 cases, and subareolar area in 10 cases. When we included 13 cases with multifocal placement and 9 cases with bilateral involvement, it was not clear in which quadrant 44 of the 134 lesions were located.

70 of the 87 cases had a preliminary diagnosis of granulomatous lobular mastitis. In 21 cases, breast carcinoma was suspected. The preliminary diagnoses of the other lesions

Table I: Clinicopathological findings of the cases $(n=90)$.

\begin{tabular}{llc}
\hline Variable & & No. of cases \\
\hline Gender & Female & 90 \\
\cline { 2 - 3 } & Male & 0 \\
\hline Age & $\leq 25$ & 7 \\
\cline { 2 - 3 } & $25-45$ & 71 \\
& $\geq 45$ & 12 \\
\hline Lesion site & Left & 43 \\
& Right & 38 \\
& Bilateral & 9 \\
\hline Initial diagnosis & Mastitis & 77 \\
& Carcinoma & 21 \\
& Abscess & 4 \\
\hline Initial treatment & Excision & 46 \\
& Steroid & 33 \\
& Immunosuppressives & 29 \\
& Combined (Steroid and & 2 \\
& Immunosuppressives) & \\
\hline Follow-up (years) & & 2.6 \\
\hline
\end{tabular}

were mastitis, periductal mastitis, abscess, fat necrosis and intraductal papilloma.

Radiologic imaging of 58 patients (64.4\%) was obtained. Ultrasonography results showed an irregularly limited hypoechoic area and dense-content fluid collection.

57 cases were biopsied and 27 cases were surgically resected. It was observed that the diagnostic information of 5 patients (including 2 patients who were referred to us for consultation) could not be obtained; and one patient's diagnostic information could not be gathered; one patient was diagnosed by fine needle aspiration material.

Histopathological evaluation of 90 cases revealed nonnecrotizing granulomas involving lobule-restricted, epithelioid histiocytes and Langhans-type multinuclear giant cells (Figure 1). There was no case of necrosis, including one case with a history of tuberculosis (Figure 2). The lesions were also assessed in terms of histopathological characteristics which made us consider malignancy such as a neoplastic formation, cellular atypia, pleomorphism, mitotic activation, and stromal desmoplasia; however, no findings that indicated malignancy could be found in morphological and immunohistochemical assessments (pan- cytokeratin, CD68, CD45, Calponin). PAS, Gram and Acid fast histochemical staining was used for all cases, but none of them was positive for any microorganisms.

Chronic complications were detected in 28 cases (31.1\%) including 15 cases of fistula and 13 cases of recurrence.

Surgical treatment was applied to $46(51.1 \%)$ of the cases as excision or breast-conserving surgery. Thirty-three (33) of the 64 patients, including those who underwent

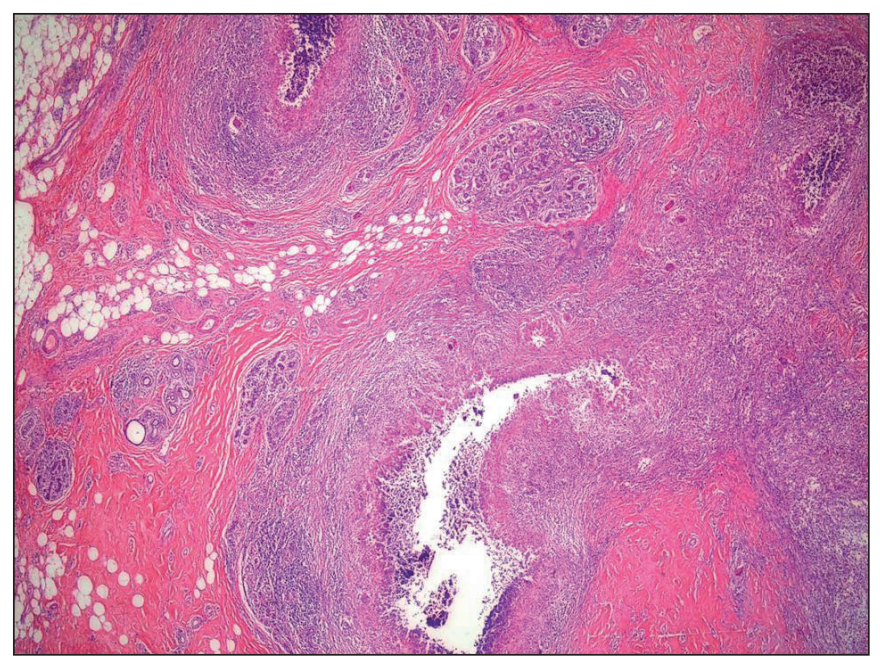

Figure 1: Breast tissue showing granuloma with histiocytes, Langhans' giant cells, plasma cells and lymphocytes (H\&E; x100). 
surgical treatment, were given steroids, 29 were given immunosuppressives and 2 were given combined therapy (steroids and immunosuppressives).

16 lesions were accompanied by fibrocystic changes in the lesion. Non-atypical intraductal hyperplasia, ductus ectasia, sclerosing adenosis, atypical intraductal hyperplasia, radial scar, apocrine metaplasia, microcalcification, fibroadenomatoid nodule and periductal mastitis were other lesions accompanying granulomatous lobular mastitis. In 2 recurrent cases (2.2\%), lesion-associated ductal carcinoma in situ (cribriform type) was detected (Figure 3).

\section{DISCUSSION}

When evaluated specifically, granulomatous lobular mastitis constitutes $24 \%$ of all inflammatory diseases of the breast. The incidence of granulomatous lobular mastitis is still unclear $(3,10)$. Although no ethnic predisposition has been documented, the number of granulomatous lobular mastitis case reports is generally high in Mediterranean countries such as Turkey, Jordan, and Asian countries such as China, and Malaysia (11). In our 12-year pathology archive, granulomatous lobular mastitis cases constitute $6.02 \%$ of all breast lesions.

Granulomatous lobular mastitis mostly occurs in young fertile women; and is often associated with pregnancy and lactation $(12,13)$. In a study of Al-Khaffaf et al., the mean age of the 18 granulomatous lobular mastitis patients was 36 (14). In our study, the mean age was found to be 34 in 90 cases ranging from 21 to 60 years. At the time of diagnosis, 3 cases were pregnant, while 3 cases were in the breastfeeding period.

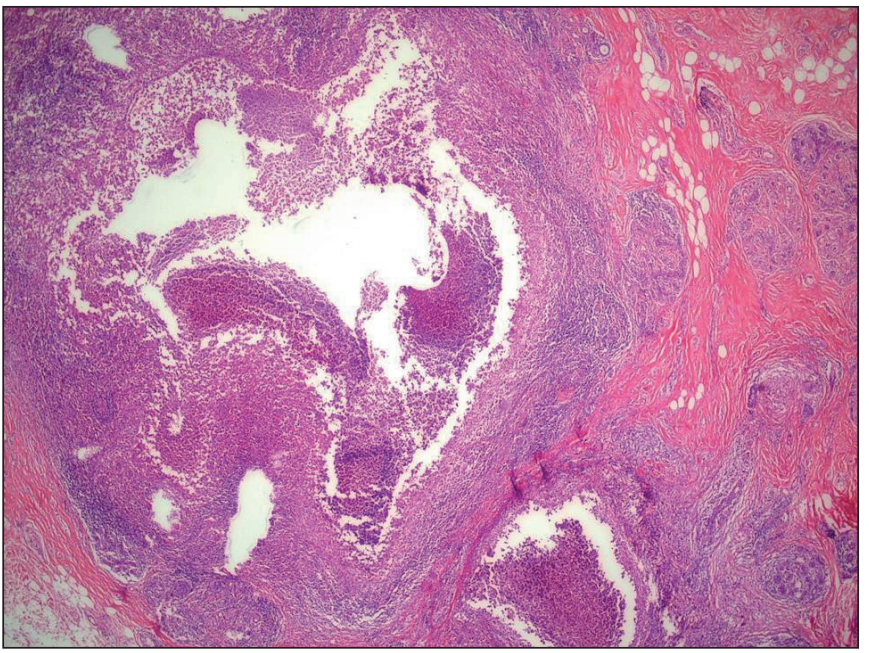

Figure 2: Perilobular chronic inflammation with granuloma formation (H\&E; $\mathrm{x} 40)$.
Patients with granulomatous lobular mastitis frequently present with unilateral painful masses in the mammary gland. These symptoms may be accompanied by symptoms such as discharge, rash on the nipple, edema, inversion, orange-peel sign and lymph node enlargement. The lesions may be located on any quadrant of the mammary gland as well as bilaterally $(15,16)$. In our study, the most frequent clinical presentation was complaint of a mass, followed by pain. Lesions were localized with $47.77 \%$ on the left, $42.22 \%$ on the right breast and $10 \%$ bilaterally. In a study performed by Korkut et al., it was found that the lesion was located in the left breast in 35 of 73 cases with granulomatous lobular mastitis, which was also consistent with our study (6). However, there are reports in the literature showing right breast localization is more dominant $(4,15)$.

The most common finding detected in mammographic imaging is focal asymmetric nodules, which do not have sharp borders and do not contain microcalcifications. Ultrasonographic findings are irregularly limited hypoechoic masses with increased parenchyma echogenicity. Magnetic Resonance imaging findings are not specific, but a study by Poyraz et al. suggested that the presence of a lesion showing increased peripheral contrast may strongly suggest granulomatous lobular mastitis (17). However, it should not be forgotten that the radiological findings of granulomatous lobular mastitis are not characteristic and do not provide benefit in distinguishing between benign and malignant disease (18-21). Ultrasonography results in our study showed an irregularly limited hypoechoic area and a concentrated fluid collection.

In terms of macroscopic evaluations, the lesion could be distinguished from the normal breast tissue, and had a gray-

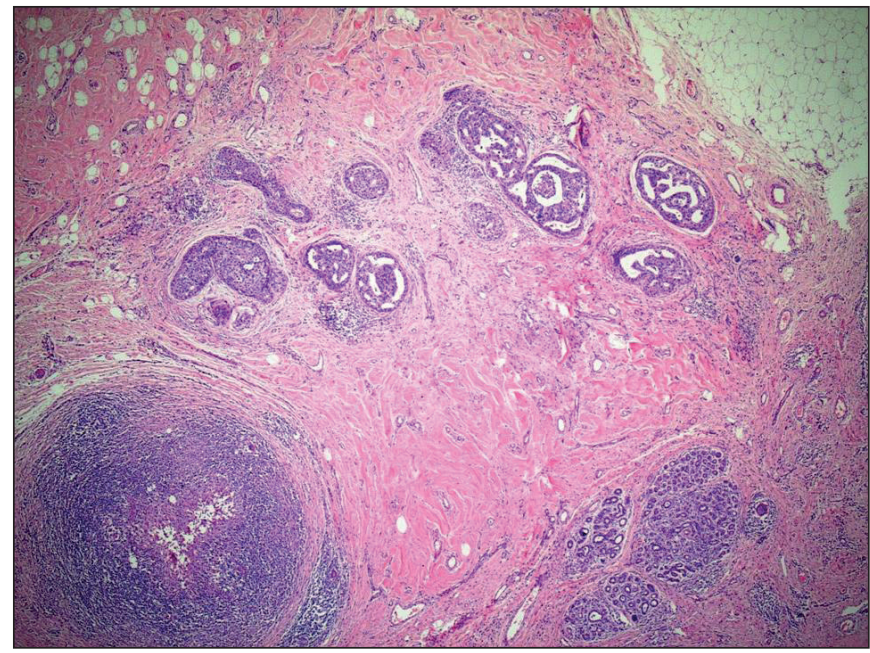

Figure 3: Moderate-nuclear grade, necrosis-free ductal carcinoma in situ co-existing with granulomatous mastitis (H\&E; $\mathrm{x} 40$ ). 
white color with a border of relatively irregular appearance and nodularity (22).

Histopathological evaluation of granulomatous lobular mastitis is characterized by the presence of granulomas, including lobulocentric lymphocytes, plasma cells, epithelioid histiocytes and multinuclear giant cells. Granulomas often involve neutrophils; and necrosis may occasionally may be seen, but caseous necrosis is not expected $(13,22)$. In our study, no necrosis was observed in any of the cases. There was no positive correlation with PAS, Gram and Acid fast histochemical tests performed in 90 cases in order to evaluate them in terms of microorganisms.

Chronic complications such as granulomatous lobular mastitis fistula and recurrence may develop. The recurrence rate in the literature is reported as $16-50 \%$ (23). In our cases, the recurrence rate was $14.4 \%$.

Other breast pathologies leading to granulomatous inflammation must be included in the differential diagnosis of granulomatous lobular mastitis. These include mycobacteria, fungal and parasitic infections, sarcoidosis, ductal ectasia and foreign body reactions. Indication of the causative factor of infection as mycobacteria, fungal or parasitic agents is important in the differential diagnosis. Granulomatous lobular mastitis causes lobulocentric granuloma, whereas interlobular or intralobular granulomatous structures are observed in sarcoidosis and periductal granulomatous structures can be seen in ductal ectasia. Being rich in neutrophils is another distinguishing feature of granulomas of granulomatous lobular mastitis (15).

Another important lesion to be distinguished from granulomatous lobular mastitis is breast carcinomas. The most common clinical manifestation of granulomatous lobular mastitis is complaint of a breast mass, as well as symptoms such as nipple retraction, ulceration, and lymph node enlargement, which are the characteristics that lead to the differential diagnosis with breast carcinomas. In addition, a finding of a solid mass with limited and irregular margins on ultrasonography is another characteristic of breast carcinomas. This lesion, which clinically and radiologically can be confused with carcinoma, rarely coexists with breast carcinoma. In the literature, four cases were reported as chronic granulomatous lobular mastitis, which were associated with the coexistence of breast carcinoma and granulomatous lobular mastitis $(6-8,23-$ 25).

The ideal treatment of granulomatous lobular mastitis is still unclear. Corticosteroids are among the first treatment options. Immunosuppressive agents such as methotrexate or azathioprine may be used in patients who do not respond to cytotoxic agents or who suffer a recurrence after treatment. Also, in these cases, surgical excision is an option but surgery should be avoided as the primary treatment option because of the possibility of chronic complications such as fistula formation and cosmetic problems and increase in the risk of recurrence (26-30). In our study, 5 cases of recurrence were primarily treated by surgery. The fistula was fully present at the time of initial diagnosis and was not associated with surgical treatment.

In conclusion, granulomatous lobular mastitis mimics breast carcinoma clinically and radiologically, and is a rare disease that should be emphasized due to the lack of a clear finding other than those on histopathological evaluation. However, it should be kept in mind that granulomatous lobular mastitis can rarely be found with breast carcinoma. In the literature, four cases reported as chronic granulomatous mastitis were associated with breast carcinoma and granulomatous lobular mastitis coexistence. The etiology of cancer development in cases of granulomatous lobular mastitis is still uncertain.

\section{CONFLICT of INTEREST}

The authors declare no conflict of interest.

\section{REFERENCES}

1. Azlina AF, Ariza Z, Arni T, Hisham AN. Chronic granulomatous mastitis: Diagnostic and therapeutic considerations. World J Surg. 2003;27:515-8.

2. Kessler E, Wolloch Y. Granulomatous mastitis: A lesion clinically simulating carcinoma. Am J Clin Pathol. 1972;58:642-6.

3. Erozgen F, Ersoy YE, Akaydin M, Memmi N, Celik AS, Celebi F, Guzey D, Kaplan R. Corticosteroid treatment and timing of surgery in idiopathic granulomatous mastitis confusing with breast carcinoma. Breast Cancer Res Treat. 2010;123:447-52.

4. Going JJ, Anderson TJ, Wilkinson S, Chetty U. Granulomatous lobular mastitis. J Clin Pathol. 1987;40:535-40.

5. Altintoprak F, Kivilcim T, Ozkan OV. Aetiology of idiopathic granulomatous mastitis. World J Clin Cases. 2014;2:852-8.

6. Korkut E, Akcay MN, Karadeniz E, Subasi ID, Gursan N. Granulomatous mastitis: A ten-year experience at a university hospital. Eurasian J Med. 2015;47:165-73.

7. Nath VG, Sahoo R, Sahoo A, Barad JK Arun KA. Idiopathic granulomatous mastitis: A clinical puzzle in breast lump cases. J Clin Diagn Res. 2017;11:PD14-PD15.

8. Limaiem F, Khadhar A, Hassan F, Bouraoui S, Lahmar A, Mzabi S. Coexistence of lobular granulomatous mastitis and ductal carcinoma: A fortuitous association? Pathologica. 2013;105:35760.

9. Kaviani A, Zand S, Karbakhsh M, Azmoudeh Ardalan F. Synchronous idiopathic granulomatosis mastitis and breast cancer: A case report and review of literature. Arch Breast Cancer. 2017;4:32-6. 
10. Mazlan L, Suhaimi SN, Jasmin SJ, Latar NH, Adzman S, Muhammad R. Breast carcinoma occurring from chronic granulomatous mastitis. Malays J Med Sci. 2012;19:82-5.

11. Handley WS. Chronic mastitis and breast cancer. Br Med J. 1938;2:113-38.4.

12. Vinayagam R, Cox J, Webb L. Granulomatous mastitis: A spectrum of disease. Breast Care (Basel). 2009;4:251-4.

13. Baslaim MM, Khayat HA, Al-Amoudi SA. Idiopathic granulomatous mastitis: A heterogeneous disease with variable clinical presentation. World J Surg. 2007;31:1677-81.

14. Al-Khaffaf B, Knox F, Bundred NJ. Idiopathic granulomatous mastitis: A 25-year experience. J Am Coll Surg. 2008;206:269-73.

15. Lai EC, Chan WC, Ma TK, Tang AP, Poon CS, Leong HT. The role of conservative treatment in idiopathic granulomatous mastitis. Breast J. 2005;11:454-6.

16. Schnitt SJ, Collins LC. Biopsy interpretation series biopsy interpretation of the breast. 2th ed. Philadelphia: Lippincott Williams \& Wilkins;2013.47-9; 186-99.

17. Poyraz N, Emlik GD, Batur A, Gundes E, Keskin S. Magnetic resonance imaging features of idiopathic granulomatous mastitis: A retrospective analysis. Iran J Radiol. 2016;13:e20873.

18. Bani-Hani KE, Yaghan RJ, Matalka II, Shatnawi NJ. Idiopathic granulomatous mastitis: Time to avoid unnecessary mastectomies. Breast J. 2004;10:318-22.

19. Kiyak G, Dumlu EG, Kilinc I, Tokaç M, Akbaba S, Gurer A, Ozkardes AB, Kilic M. Management of idiopathic granulomatous mastitis: Dilemmas in diagnosis and treatment. BMC Surg. 2014;14:66.

20. Larsen LJH, Peyvandi B, Klipfel N, Grant E, Iyengar G. Granulomatous lobular mastitis: Imaging, diagnosis, and treatment. Am J Roentgenol. 2009;193:574-81.

21. Cheng L, Reddy V, Solmos G, Watkins L, Cimbaluk D, Bitterman P, Ghai R, Gattuso P. Mastitis, a radiographic, clinical, and histopathologic review. Breast J. 2015;21:403-9.
22. Gautier N, Lalonde L, Tran-Thanh D, El Khoury M, David J, Labelle M, Patocskai E, Trop I. Chronic granulomatous mastitis: Imaging, pathology and management. Eur J Radiol. 2013;82:e16575.

23. Hoda SA, Brogi E, Koerner FC, Rosen PP. Rosen's breast pathology. 4th ed. Philadelphia: Lippincott Williams \& Wilkins;2014. 47-9.

24. Gurleyik G, Aktekin A, Aker F, Karagulle H, Saglamc A. Medical and surgical treatment of idiopathic granulomatous lobular mastitis: A benign inflammatory disease mimicking invasive carcinoma. J Breast Cancer. 2012;15:119-23.

25. Limaiem F, Khadhar A, Hassan F, Bouraoui S, Lahmar A, Mzabi S. Coexistence of lobular granulomatous mastitis and ductal carcinoma: A fortuitous association? Pathologica. 2013;105:35760.

26. Kaviani A, Zand S, Karbakhsh M, Azmoudeh Ardalan F. Synchronous idiopathic granulomatosis mastitis and breast cancer: A case report and review of literature. Arch Breast Cancer. 2017;4:32-6.

27. Mazlan L, Suhaimi SN, Jasmin SJ, Latar NH, Adzman S, Muhammad R. Breast carcinoma occurring from chronic granulomatous mastitis. Malays J Med Sci. 2012;19:82-5.

28. Mahlab-Guri K, Asher I, Allweis T, Diment J, Sthoeger ZM, Mavor E. Granulomatous lobular mastitis. Isr Med Assoc J. 2015;17:476-80.

29. Asoglu O, Ozmen V, Karanlik H, Tunaci M, Cabioglu N, Igci A, Selcuk UE, Kecer M. Feasibility of surgical management in patients with granulomatous mastitis. Breast J. 2005;11:108-14.

30. Sakurai K, Fujisaki S, Enomoto K, Amano S, Sugitani M. Evaluation of follow-up strategies for corticosteroid therapy of idiopathic granulomatous mastitis. Surg Today. 2011;41:333-7. 